\title{
HISTÓRIAS SOBRE A REGIÃO RURAL: MEMÓRIAS FEMININAS E PATRIMÔNIO CULTURAL
}

\section{STORIES ON COUNTRY LIFE: FEMALE MEMORIES AND CULTURAL LEGACY}

\section{HISTORIAS SOBRE LA REGIÓN RURAL: MEMORIAS FEMENINAS $Y$ PATRIMONIO CULTURAL}

\section{Janine Gomes da Silva ${ }^{1}$}

\section{RESUMO:}

Localizado no contexto dos estudos de gênero, memória e patrimônio cultural, o presente artigo apresenta algumas discussões sobre o cotidiano e a culinária de algumas estradas que compõe a região rural da cidade de Joinville, situada no nordeste do estado de Santa Catarina. Frente às novas preocupações com a preservação do patrimônio cultural, bem como da relação entre turismo e cultura, nos cabe perguntar como diferentes moradores vem (re)construindo significados sobre a cidade, espaço por excelência privilegiado para inscrever, cotidianamente, outras narrativas sobre patrimônio, "lugares de memória" e "maneiras de fazer". Assim, procuramos problematizar a partir da metodologia da História Oral, especialmente a partir de memórias femininas, aspectos do patrimônio cultural da cidade de Joinville, contribuindo com a historiografia local e, principalmente, com diferentes reflexões sobre este patrimônio da região, em seu aspecto material e imaterial.

Palavras-chave: Gênero. Memória. Patrimônio cultural.

\section{ABSTRACT:}

Contextualized in the studies on gender, historical memory and cultural legacy, this article discusses some data related to the country people's daily way of life, including cookery, observed in the rural area surrounding the city of Joinville, located in the Northeast of the Brazilian Southern State of Santa Catarina. Due to the new approaches on the preservation of cultural legacies connected to tourism and culture itself, there comes the question about how the different country people still have been (re)-constructing their reference and meanings, dealing with their town life the ideal spot for inscribing, daily, other narratives on legacy, "places of memory" and "ways to do it". Thus, we have tried to register aspects of the cultural legacy of the city of Joinville, using the Oral History methodology and taking special interest in women's accounts, contributing, this way, to the local historiography which leads us to reflections on the regional legacy of material and nonmaterial aspects.

Key-words: Gender. Memory. Cultural legacy.

${ }^{1}$ Doutora em História. Professora do Departamento de História e do Programa de Mestrado em Patrimônio Cultural e Sociedade da Universidade da Região de Joinville e Historiadora do Arquivo Histórico de Joinville. E-mail: janine.gomes@univille.net

R. Inter. Interdisc. INTERthesis, Florianópolis, v.6, n.2, p. 30-44, jul./dez. 2009 


\section{RESUMEN:}

Ubicado en el contexto de los estudios de género, memoria y patrimonio cultural, este artículo presenta algunas discusiones sobre el cotidiano y la culinaria de algunas carreteras que componen la región rural de la ciudad de Joinville, situada en el nordeste del Estado de Santa Catarina, Brasil. Frente a la nuevas preocupaciones con la preservación del patrimonio cultural, como también con la relación entre turismo y cultura, se puede preguntar cómo diferentes habitantes vienen (re)construyendo significados sobre la ciudad, lugar privilegiado para inscribir, cotidianamente, otras narrativas sobre patrimonio, "lugares de memoria" y "maneras de hacer". Así, buscamos problematizar a partir de la metodología de la Historia Oral, especialmente a partir de memorias femininas, aspectos del patrimonio cultural de la ciudad de Joinville, contribuyendo con la historiografía local y, principalmente, con diferentes reflexiones sobre el patrimonio cultural de la región, en su aspecto material e inmaterial.

Palabras clave: Género. Memoria. Patrimonio cultural.

"No fundo, a cozinha me inquieta...", parafraseando o título de um dos capítulos do segundo volume de $A$ invenção do cotidiano (CERTEAU; GIARD; MAYOL, 1997) poderia se constituir num resumo das inquietações que vem acompanhando o desenvolvimento de uma pesquisa sobre a região rural de Joinville, cidade localizada no nordeste de Santa Catarina. Na expectativa de problematizar questões relacionadas com o patrimônio cultural desta cidade, especialmente a partir da perspectiva da memória e das lembranças de moradoras/es, estava interessada em pesquisar histórias sobre o patrimônio cultural, tanto material como imaterial, por intermédio do projeto "Lugares de memória, memórias de lugares... Diferentes olhares para o patrimônio cultural de Joinville", financiado pelo FAP/UNIVILLE. Todavia, se inicialmente as preocupações estavam mais voltadas às questões relacionadas ao patrimônio edificado, no decorrer da pesquisa a temática da culinária tomou uma proporção cada vez maior para pensar as relações de gênero presentes nas "maneiras de fazer", de homens e mulheres que estão ligados ao chamado turismo rural da região.

Assim, a partir da metodologia da História Oral, que tem como principal característica o emprego de narrativas orais, tendo como referência entre outros autores Alberti (2004), Amado e Ferreira (1998), Bosi (1995) e Portelli (1997), procuramos conhecer, especialmente a partir das memórias, aspectos da história cidade de Joinville, evidenciando histórias de diferentes lugares, casas e prédios, instituições, períodos e práticas cotidianas, vivenciadas no decorrer do século $\mathrm{XX}$,

R. Inter. Interdisc. INTERthesis, Florianópolis, v.6, n.2, p. 30-44, jul./dez. 2009 
contribuindo com a historiografia local e, principalmente, com diferentes reflexões sobre o patrimônio cultural da região, em seu aspecto material e imaterial. Neste sentido as reflexões de autores como Abreu e Chagas (2003), Arruda (2006), Choay (2001), Ferreira (2006) e Yúdice (2004) foram importantes para compreender como, na contemporaneidade, se constroem diferentes discursos sobre patrimônio cultural.

No decorrer do século XX várias foram as interpretações sobre o que é patrimônio, todavia, no Brasil, é partir da Constituição da República Federativa 1988 que o conceito de patrimônio é ampliado, notadamente em seu o artigo 216, quando afirma que "constituem patrimônio cultural brasileiro os bens de natureza material e imaterial, tomados individualmente ou em conjunto, portadores de referência à identidade, à ação, à memória dos diferentes grupos formadores da sociedade brasileira" (1989, p. 86). É neste contexto que temos o reconhecimento do chamado "patrimônio cultural imaterial ou intangível", que salienta, entre outros aspectos, "as formas de expressão" e "os modos de criar, fazer e viver". Posteriormente, o Decreto 3.551, de 4 de agosto de 2000, "Institui o Registro de Bens Culturais de Natureza Imaterial que constituem patrimônio cultural brasileiro", refletindo discussões importantes nesta área. Assim, intensificam-se no início do século XXI outros olhares para problematizar quais são as "maneiras de fazer" que podem ser "merecedoras" de serem considerados bens culturais. Certamente trata-se de uma temática ainda recente, e os vários dossiês que apresentam alguns bens que vão ao encontro desta nova perspectiva podem ser consultados no site do Instituto do Patrimônio Histórico e Artístico Nacional - IPHAN, como por exemplo, o "Ofício das Baianas de Acarajé" e o "Ofício das Paneleiras de Goiabeiras", do Espírito Santo. Mas, vários estudos podem ser destacados relacionados à história da alimentação, como por exemplo, Meneses e Carneiro (1997), Menasche (2007), Carneiro (2005), Santos (2005) e Abdala (2006).

Convém ressaltar que não é objetivo da pesquisa que desenvolvemos apontar ofícios ou saberes que devem ser protegidos na região, mas, problematizar algumas questões que tangenciam os olhares sobre o patrimônio cultural da cidade, notadamente, do patrimônio imaterial.

Deste modo, se é tão difícil procurar perscrutar quais são as referências que podem ser compreendidas como bens culturais imateriais ou intangíveis, a realização de entrevistas orais contribui para a escuta de diferentes representações

R. Inter. Interdisc. INTERthesis, Florianópolis, v.6, n.2, p. 30-44, jul./dez. 2009 
sobre aquilo que pode ser referenciado como bem cultural de uma determinada região. Assim, por meio de entrevistas, concedidas principalmente por mulheres, preferencialmente nascidas antes de 1950, que podem de modo privilegiado, narrar histórias sobre a cidade de Joinville, suas transformações e permanências, iniciamos uma escuta sobre as histórias sobre a região rural, bem como, a relação entre turismo e cultura que, sobremaneira, destaca as "maneiras de fazer" relacionadas à culinária das moradoras das estradas rurais.

Explorar algumas histórias da cidade tomando como ponto de partida narrativas de mulheres, pode se constituir, de certa maneira, uma forma de compreender as "fronteiras" estabelecidas nos "espaços para homens e mulheres", ou nas práticas tidas como "de homens ou de mulheres", evidentemente sem naturalizar os papéis femininos e masculinos como definidoras de uma "memória feminina", mas atenta as experiências concretas das mulheres, que implica necessariamente nas suas relações com o masculino e com relações de poder, pois, segundo Joan Scott, gênero é um "elemento constitutivo das relações sociais baseado nas diferenças percebidas entre os sexos, e o gênero é um primeiro modo de dar significado às relações de poder" (1990, p. 14). Assim, perspectivar dos estudos de gênero para olhar a cidade é uma maneira de observar, na urdidura do cotidiano como se "faz o traçado da cidade, espaço social, étnico e sexuado" (PERROT, 2005, p. 360).

E é, nesse espaço, que podemos observar como, recentemente, a organização de alguns grupos de mulheres rurais tem contribuído com a região agrícola da cidade. Vários destes grupos estão ligados a Fundação 25 de Julho, entidade criada em 1967 para, entre outras ações, prestar assistência técnica aos agricultores. Esta Fundação tem diversos programas, entre eles o de Turismo Rural e de Desenvolvimento da Mulher Rural, este último com aproximadamente 500 mulheres divididas em 22 grupos. Convém destacar que as reflexões presentes neste texto estão relacionadas a quase trinta entrevistas, realizadas principalmente com mulheres de três localidades, Quiriri, Estrada Mildau e Estrada Bonita, esta última bastante conhecida como referência de turismo rural na agricultura familiar a partir da década de 1990.

Segundo Tulik, de maneira ampla, podemos entender turismo rural como "um conjunto de atividades desenvolvidas no espaço rural" (2003, p. 43). É na região da R. Inter. Interdisc. INTERthesis, Florianópolis, v.6, n.2, p. 30-44, jul./dez. 2009 
Estrada Bonita que mais podemos observar, na cidade de Joinville, maior investimento no "oferecimento" dos bens culturais da região como atrativos turísticos culturais. Ao passear por esta estrada, podemos além de usufruir da paisagem como um "recurso turístico", conforme aponta Pires (2001), conhecer os modos e maneiras de fazer das/os moradoras/es, especialmente relacionados a agricultura familiar e a culinária. $E$, numa intricada relação de turismo com cultura, neste espaço, são valorizadas as receitas ditas como "do tempo dos imigrantes", pois, é bom lembrar, a cidade de Joinville foi colonizada por imigrantes, muitos de origem germânica, a partir de 1851. Neste sentido, as maneiras de fazer as receitas "de origem" são também significativas na construção da identidade local. Uma identidade que é costumeiramente relacionada ao passado de imigração alemã da região e, desta maneira, a valorização de tradições germânicas. Assim, com relação à culinária, a maioria das entrevistadas fez referência aos pães, cucas, bolos, biscoitos, geléias e musses produzidos na região, como importantes práticas relacionadas ao tempo da imigração. Algumas entrevistadas fizeram referência às bolachas de mel e ao gemüse como um dos pratos da culinária que são referências por lembrarem as receitas "daquele tempo". Em publicação recente o gemüse é citado como um dos pratos típicos que ainda faz parte de descendentes dos imigrantes em várias regiões do estado de Santa Catarina. Um prato simples, com batata, couve, cebola, alho e costelinha de porco defumada, que era preparado com antecedência para ser servido no retorno das missas de domingo (ORIGEM, s/d, p. 48). Para muitos este prato é lembrado como um prato bem antigo, pois, diariamente as mulheres cozinhavam e já serviam o almoço, mas, aos domingos, também iam à missa e na volta, tinham pouco tempo para providenciar o almoço. Já, uma de nossas entrevistadas lembra-se do gemüse como uma "maionese quente": uma mistura de folhas de couve, batatinha, farofa, cebola de cabeça, cebolinha verde e salsinha. ${ }^{2}$

Aos poucos, podemos perceber que começa fazer efeito de sentido para as/os moradoras/es da região rural a importância da preservação de suas práticas culturais relacionadas à culinária. Inicialmente, podemos dizer que são as ações estimuladas pelo turismo rural que fomentam a intenção de muitas famílias em permanecer nas propriedades investindo na produção de produtos artesanais para vender para os visitantes da cidade (leia-se os moradores da região central/urbana

${ }^{2}$ MAFRA, Ana Maria M. Entrevista concedida a Maria Elisa Horn Iwaya. Joinville, 14 out. 2008.

R. Inter. Interdisc. INTERthesis, Florianópolis, v.6, n.2, p. 30-44, jul./dez. 2009 
da cidade de Joinville) e dos "turistas de fora". Neste sentido, parece interessante a reflexão de Poulain (2004, p. 38), ao mencionar que "a patrimonialização do alimentar e do gastronômico emerge num contexto de transformação das práticas alimentares vividas no modo da degradação e mais amplamente no risco de perda da identidade". E, destaca-se, é o discurso de uma "identidade germânica" que acompanha as bolachas, as cucas e outras delícias produzidas na maioria das residências da região rural que são parceiras da maioria dos programas de turismo rural da cidade. Talvez, a ratificação de tais discursos infere para a necessidade das/os descendentes dos imigrantes de preservarem bens culturais que são signos importantes das suas histórias de vida num momento onde a diversidade cultural está mais presente no cenário da cidade. E é aí que a questão da culinária passa a ter uma importância ímpar na relação turismo e patrimônio cultural estando diretamente relacionada aos saberes femininos. Não que os homes da região não cozinhem ou também não produzam para vender, mas, de maneira geral, são as mulheres que se dedicam aos afazeres culinários.

As diferentes narrativas das mulheres que entrevistamos, falam de turismo, de lidas da casa, da propriedade rural, mas, principalmente, atribuem sentidos as receitas elaboradas carinhosamente como signos do que é representativo da região. Muitas delas como Anita ensinam a fazer, passam as receitas, muitas vezes passo a passo, como que querendo dividir com as entrevistadoras, como por exemplo, quando falou do Platten Kuchen, ou a cuca, com farofa e fermento de pão: "Para a farofa é utilizado margarina, um pouco de banha, trigo, açúcar, baunilha ou raspa de limão também. Se quiser acrescentar banana, pode ser fatiada ou amassada com garfo, e polvilhar com canela e açúcar". ${ }^{3}$ Saberes ordinários, mas que, de tão simples, tornam-se quase enigmáticos, pois, o ponto de cada quitute, isso depende da experiência adquirida ao longo dos anos. Uma experiência feminina, podemos dizer, pois, desde pequenas, aprenderam com suas mães e outras mulheres da família os detalhes da elaboração de cada prato. Neste aspecto podemos observar uma questão de gênero. Como já mencionamos, os homens por vezes também se dedicam a produzir alguns alimentos, alguns estão a frente das cozinhas de

${ }^{3}$ HATENNHAUER, Anita. Entrevista concedida a Valéria König Esteves e Maria Elisa Horn Iwaya. Joinville, 14 out. 2008.

R. Inter. Interdisc. INTERthesis, Florianópolis, v.6, n.2, p. 30-44, jul./dez. 2009 
restaurantes, como Rudolfo, que entrevistamos na Estrada Bonita ${ }^{4}$, todavia, a riqueza dos detalhes são mais significativos nas narrativas da mulheres.

De maneira geral, as mulheres da região que cozinham (e evidentemente não são todas), quando são perguntadas sobre a culinária local que é oferecida aos turistas e como preparam, compartilham histórias e experiências, mas, principalmente, indicam pistas sobre os saberes femininos da região rural. Muitas se emocionam e demonstram certo estranhamento, pois, possivelmente para elas, suas práticas cotidianas, de "tão comuns", não interessariam pesquisadoras da Universidade. Falas singelas como a de Regina ao ensinar a fazer pão e sugerir que deveria assar no forno à lenha "ele é mais gostoso". 5 A fala destas mulheres constitui-se apenas em exemplos, mas que de maneira geral podem ser estendidas para a maioria das entrevistas realizadas. Mudam as receitas, os segredinhos, mas, as maneira de fazer de cada uma indica que a riqueza da culinária como uma referência cultural é significativa para a relação turismo rural e patrimônio cultural. Dos segredos que aprendemos ou tentaram nos ensinar, é possível compreender as palavras de Luce Giard "desde que alguém se interessa pela arte culinária, pode constatar que ela exige uma memória múltipla: memória de aprendizagem, memória dos gestos vistos, das consistências [...]" (CERTEAU; GIARD; MAYOL, 1997, p. 219).

Para alguns o tema da culinária "está na moda", cada vez mais programas de televisão dedicam-se a ensinar receitas, umas mais simples, outras mais sofisticadas. Os cursos de gastronomia estão aumentando e, a oferta da culinária como souvenir para turista ganha cada vez mais destaque. No retorno da Estrada Bonita podemos trazer cucas, geléias, bolachas, entre outros quitutes. Todavia, para além dos modismos, cabe perguntar como a culinária de algumas estradas que compõe a região rural da cidade de Joinville vem ganhando destaque nas últimas décadas.

Em Joinville, como mencionamos, pode-se verificar uma estreita relação da culinária, embora não oficial por meio de algum registro ou diagnóstico, como um patrimônio cultural. As receitas de cucas, bolachas de nata, por exemplo, narradas

${ }^{4}$ GERMANN, Rudolfo. Entrevista concedida a Valéria König Esteves, Maria Elisa Horn Iwaya e Janine Gomes da Silva. Joinville, 18 out. 2008.

${ }^{5}$ GALICKI, Regina. Entrevista concedida a Valéria König Esteves. Joinville, 08 out. 2008.

R. Inter. Interdisc. INTERthesis, Florianópolis, v.6, n.2, p. 30-44, jul./dez. 2009 
durante a realização das entrevistas compõem um mosaico culinário ao mesmo tempo em que aponta para uma simbologia interessante para compreender as alterações e/ou permanências que ocorreram no cotidiano, principalmente das mulheres ligadas aos grupos de mulheres rurais. Neste sentido, cabe observar a presença de dois aspectos, trabalhados por outras autoras em pesquisas diversas, mas que contribuem para compreender a importância do uso da categoria de análise gênero na narrativa histórica ao problematizar as relações entre homens e mulheres, neste caso, moradores da região rural de Joinville. Primeiro, as "percepções sobre esferas separadas de gênero", como menciona Bila Sorj, pois, "a percepção de que aos homens e às mulheres correspondem a esfera de ação distintas ainda desfruta de ampla legitimidade entre nós [...]". Esta autora observou algumas tendências na percepção das desigualdades relativas à divisão sexual do trabalho, onde persiste a idéia do trabalho masculino como para "ganhar dinheiro" e o feminino como "cuidar da casa e família". (SORJ, 2005, p. 81). Ora, no caso de algumas propriedades rurais estudadas, o homem também trabalha "fora", em algumas indústrias da cidade, mas, o cuidar da casa e da família, para as mulheres, também pressupõe cuidar da propriedade e produzir, por exemplo as bolachas, cucas e geléias, para vender aos turistas. Ou seja, também "ganham dinheiro", mas, os seus trabalhos não são, por elas mesmas, às vezes, valorizados. Uma das senhoras que tentamos entrevistar, apesar de todo o trabalho desenvolvido na propriedade, desde o início do projeto de turismo rural, não se dispôs a gravar uma entrevista, pois, segundo ela, "era o marido que sabia". Assim, outro aspecto a ser observado é o da invisibilidade do trabalho feminino, bem como, uma "indissociabilidade entre trabalho feminino assalariado e familiar", onde o trabalho da mulher, não remunerado, é "confundido com o não trabalho, com a não atividade econômica" (PANZUTTI, 2006, p. 26).

Embora atualmente possa ser percebida uma maior presença da importância dos trabalhos das mulheres da região rural para o desenvolvimento do turismo rural, as questões anteriormente citadas merecem ser observadas para compreender, por exemplo, porque algumas mulheres que tentamos entrevistar, apesar de mencionarem que "tocavam o turismo", por intermédio da culinária oferecida em suas propriedades, ao mesmo tempo diziam que eram atividades "simples", que aprenderam "desde meninas".

R. Inter. Interdisc. INTERthesis, Florianópolis, v.6, n.2, p. 30-44, jul./dez. 2009 
Mas, aos poucos, a culinária desta região vem sendo conhecida. Talvez resida na valorização contemporânea destes fazeres uma característica apontada pela Chef Sonia Ezgulian ao comparar a cozinha a uma "ponte", a um "meio de comunicação" (GUSTO, 2007, p. 41). Destaca-se que estas observações estão presentes num dos números da revista Gusto que se dedicou ao tema "La table au fémin". Neste mesmo número, a historiadora Michelle Perrot, ao tematizar o lugar das mulheres na cozinha, salienta que a cozinha também é lugar de poder e de sedução, lugar de uma preocupação constante das mulheres em diferentes tempos e espaços (PERROT, 2007, p. 11). Assim, podemos dizer, a relação da culinária com as discussões referentes a patrimônio perspectivada pelo olhar dos estudos de gênero pode contribuir com outras interpretações para as histórias cotidianas vivenciadas na região rural, pois, a alimentação pode ser entendida como um traço cultural ( e não meramente categorizada como um dado natural relacionado a fome e a necessidade de se alimentar). Mas, cabe salientar a importância, segundo Gonçalves, de situar as discussões relacionadas ao "sistema culinário" brasileiro num conjunto de "relações de interdependência" (2007, p. 171). Os usos simbólicos dos alimentos precisam ser de maneira mais ampla compreendidas. No caso da culinária das regiões pesquisadas, ao que tudo indica, podemos verificar uma nítida relação da valorização de uma culinária associada ao um passado de imigração com as ações contemporâneas empreendidas pelo turismo rural. E, neste aspecto, as mulheres da região rural costumam ser destacadas. Em 2003, ao prepararem o $10^{\circ}$ encontro dos grupos de desenvolvimento da mulher rural de Joinville, uma reportagem jornalística destacava as palavras da extensionista rural Irma Bertoldi para explicar a importância do projeto dos grupos destas mulheres pra o desenvolvimento da região rural. Segundo ela, foi por intermédio deste projeto que as mulheres da região conquistaram importantes vitórias, "como a implantação dos projetos de turismo rural e das agroindústrias artesanais, que passaram a representar a agregação de valor para centenas de pequenas propriedades rurais" (A NOTÍCIA, 05 jun. 2003, p. 14). Na mesma reportagem Irma também destacou a questão da auto-estima, pois, segunda ela, "antes do surgimento do projeto a maioria das mulheres do meio rural tinha vergonha de ser da agricultura". Evidentemente as observações de Irma poderiam não dar conta da diversidade de opiniões relacionadas ao tema, tendo em vista, ser a idealizadora e coordenadora R. Inter. Interdisc. INTERthesis, Florianópolis, v.6, n.2, p. 30-44, jul./dez. 2009 
deste projeto da Fundação Municipal 25 de Julho. Todavia, atualmente, muitas mulheres que entrevistamos nas três regiões anteriormente citadas fazem referência ao fato de participar do grupo valorizar sua condição de agricultora. Ainda, muitas aprenderam, nos encontros semanais ou mensais, que seus trabalhos, considerados por muitas, anteriormente "apenas doméstico", são trabalhos produtivos e que além de minimizar o êxodo rural, contribuem com o desenvolvimento econômico da região. Para algumas a maior dificuldade de participar dos grupos (que são vários nas diferentes estradas da região rural), reside no fato dos maridos não aprovarem este encontros. Os encontros costumam ter como principal atrativo a confecção de produtos artesanais, muitos vendidos na Casa Krüger, localizada na rodovia SC-301, no acesso à serra Dona Francisca, no Distrito de Pirabeiraba, uma construção da década de 1920 que foi tombada e se tornou um "portal do turismo rural".

Somado ao desenvolvimento da região rural, da melhoria da auto-estima e dos esforços para o incremento do turismo rural e valorização do patrimônio da região, como a valorização das edificações mais antigas, dos engenhos, da culinária e da paisagem, pode-se observar, muitas vezes associado a estes grupos e ações, iniciativas de valorização, (re) criação e invenção de atividades como portadoras e/ou representativas de uma identidade das diferentes regiões, como por exemplo, formação de grupos folclóricos e festas, na maioria das vezes nominadas como "típicas" da cidade.

Foi neste contexto, que conhecemos algumas histórias sobre a Festa do Cará, criada em Joinville, no início da década de 1990, na região rural da cidade, na Estrada Mildau, Distrito de Pirabeiraba.

Mais ou menos vinte produtores da região cultivam cará. Há quase duas décadas, no início do mês de agosto, para comemorar a época da colheita, as/os moradoras/es da região se reúnem por intermédio da Festa do Cará para saborear diversos pratos à base deste tubérculo (como pães, cucas, bolinhos, maionese, cará com bacon) e divulgar a região como um lugar de turismo rural. De maneira geral, além da culinária mencionada por várias/os moradoras/es da região como "típica dos imigrantes alemães", a programação do evento inclui concurso de beleza, competição por produtividade, desfile, corrida em que os competidores carregam um saco de cará e bailes. A partir de diferentes narrativas foi possível perceber representações que nos remetem aos espaços de sociabilidades e divertimento na

R. Inter. Interdisc. INTERthesis, Florianópolis, v.6, n.2, p. 30-44, jul./dez. 2009 
região rural, com destaque para "as festas típicas" e "tradicionais" que enaltecem um passado de "berço germânico". Entretanto, convém lembrar que o cará não é um tubérculo típico da região de onde vieram os imigrantes alemães para Joinville ainda no século XIX. Ou seja, em novas terras, os imigrantes e seus descendentes adaptaram este tubérculo às suas antigas receitas, introduzindo, aos poucos, novos hábitos alimentares. Mas, o que chama a atenção é como que, no presente, em tempos de maior valorização do patrimônio cultural da região associado ao turismo rural, ao que tudo indica, o cará (não só a planta, mas todas as representações que a cercam como a memória dos imigrantes e a identidade germânica) toma efeito de sentido mais amplo, assumindo a força de um bem cultural tipicamente tradicional. Ou seja, uma recente "tradição", uma "tradição inventada", como diria Hobsbawm (1997).

Sobre as iguarias produzidas com o cará, ouvimos algumas mulheres da Estrada Mildau. A cada nova receita, somavam-se falas da importância do turismo rural e o fato de, para muitas mulheres, não existir nesta região o mesmo incentivo que tem, por exemplo, a Estrada Bonita. Algumas mulheres, como Rosinha6, destacaram a antiguidade da festa e a importância da culinária a base do cará para a história da região rural. Evidentemente, não pretedemos cotejar as versões sobre ser ou não um alimento típico, tradicional ou merecedor de ser entendido como uma referência cultural para toda a cidade. Todavia, cabe compreender como, para aquela região, ou para apenas alguns moradores, a culinária a partir do cará pode se constituir num vínculo com uma história a ser preservada e, portanto, compreendida como patrimônio cultural para aquela região, pois, de acordo com Maciel (2004) "uma cozinha não pode ser reduzida a um inventário, a um repertório de ingredientes, nem convertida em fórmulas ou combinações de elementos cristalizados no tempo e no espaço". Assim, é possível perceber que, mesmo sendo uma festa recente na história da cidade, a Festa do Cará traz consigo alguns significados interessantes para pensar a cidade, pois, as artes de fazer relacionadas às cozinhas também podem ser marcadores indentitários, "a cozinha pode ser operada como um forte referencial identitário, utilizado por um grupo como símbolo de uma identidade reivindicada para si" (MACIEL, 2004).

${ }^{6}$ SOMMERFELD, Rosinha. Entrevista concedida a Janine Gomes da Silva. Joinville, 20 out. 2008.

R. Inter. Interdisc. INTERthesis, Florianópolis, v.6, n.2, p. 30-44, jul./dez. 2009 
Mas, a cidade não é homogênea. Em outras estradas, com menor presença de descentes de imigrantes alemães, outras práticas e festas também são vivenciadas. Como lembraram algumas entrevistadas - também temos a "Festa do Arroz" a "Festa da Polenta". Da diversidade das práticas cotidianas destas regiões não temos muitos registros, por isso trabalhar com a memória e com a história oral possibilita diferentes reflexões sobre o patrimônio cultural da região, em seu aspecto material e imaterial. Não se trata de compreender as diferentes narrativas como "verdadeiras", pois, como já destacou Halbwachs, "cada memória individual é um ponto de vista sobre a memória coletiva, que este ponto de vista muda conforme o lugar que ali eu ocupo, e que este lugar mesmo muda segundo as relações que mantenho com outros meios" (1990, p. 51).

Por intermédio das memórias emergem narrativas que nos auxiliam a compreender como uma das tarefas mais comuns do cotidiano de muitos homens e mulheres, a culinária, pode ser significativa para a compreensão de algumas histórias da cidade. Ouvindo diferentes mulheres, percebemos que as histórias relacionadas ao preparo de alguns alimentos, como por exemplo, os "tipicamente alemães" vão descortinando outros aspectos das tramas que compõem e ou sustentam discursos sobre o patrimônio cultural. "Patrimônio para mim", dizia Anelore, "são as casas, os bens e a família". ${ }^{7}$ Aliás, destaca-se, são os turistas, os extensionistas rurais, os pesquisadores que atribuem às deferentes vivências relacionadas aos saberes da região rural o conceito de patrimônio, pois, para a maioria das/os entrevistadas/os, patrimônio é o que elas/es têm. São os filhos, a propriedade, o casamento. Mas, se a maioria não tem conceitualmente a percepção de patrimônio cultural que é potencializado na região, na prática, propiciam alguns registros do que poderíamos chamar de referenciais de bens culturais. Para algumas mulheres, possivelmente, o turismo rural não mudou significativamente suas lidas cotidianas. Todavia, para outras, o desenvolvimento da agricultura familiar associado ao turismo rural potencializando o patrimônio cultural da região, significou grandes mudanças. Os encontros com as vizinhas de outras propriedades não são tão restritos. São três horas, uma vez por semana, mas que para muitas tem um significado muito especial, pois, apesar de trabalharem juntamente com maridos e

${ }^{7}$ SCHROEDER, Anelore Artmann. Entrevista concedida a Maria Elisa Horn Iwaya. Joinville, 29 set. 2008.

R. Inter. Interdisc. INTERthesis, Florianópolis, v.6, n.2, p. 30-44, jul./dez. 2009 
filhos nas propriedades (e, como já mencionamos, algumas inclusive trabalham praticamente sozinhas, pois os maridos dividem o tempo em trabalhar nas indústrias da cidade), estes encontros são "só para elas". Ter um espaço só seu numa relação em que ainda na propriedade "quem manda é o marido", é no mínimo uma experiência que ajuda a auto-estima, pois, como mencionou Irma, muitas mulheres antes de participar destes grupos nunca tinham saído da cidade e depois, "puderam fazer passeios fora". ${ }^{8}$

Especialmente em relação à culinária, na prática são elas que detêm as "maneiras de fazer" tão significativas para as discussões acerca do patrimônio cultural, mas, simbolicamente, nas plaquinhas em várias propriedades ligadas ao turismo rural da Estrada Bonita, são os nomes deles que aparecem. São relações de poder construídas culturalmente que permeiam também as histórias da região rural.

As histórias da região são muitas... Sobre a mata, as casas, os alambiques, os engenhos, os restaurantes coloniais, as benzedeiras e as festas. Mas, indiscutivelmente, foram as práticas relacionadas à culinária que afloraram na maioria das entrevistas realizadas. Foram inúmeras receitas, vários detalhes, segredinhos, medidas, modos de fazer e, é claro, alguns truques que não foram revelados. Diferentes narrativas que possibilitam um convite a conhecer melhor as outras estradas da região rural da cidade, pois, como mencionado anteriormente "No fundo, a cozinha me inquieta...".

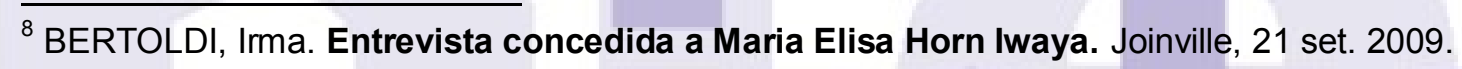

R. Inter. Interdisc. INTERthesis, Florianópolis, v.6, n.2, p. 30-44, jul./dez. 2009 


\section{REFERÊNCIAS}

ABDALA, Mônica Chaves. Sabores da tradição. Revista do Arquivo Público Mineiro, Belo Horizonte, Ano XLII, nº 2, p. 119-129, dez. 2006.

ABREU, Regina; CHAGAS, Mário (orgs.) Memória e patrimônio: ensaios contemporâneos. Rio de Janeiro: DP\&A, 2003.

ALBERTI, Verena. Ouvir contar: textos em história oral. Rio de Janeiro: FGV, 2004.

AMADO, Janaína; FERREIRA, Marieta de Moraes (orgs.). Usos e abusos da história oral. 2. ed. Rio de Janeiro: Fundação Getúlio Vargas, 1998.

ARRUDA, Gilmar. O patrimônio imaterial: a cidadania e o patrimônio dos "sem eira nem beira". Diálogos, DHI/PPH/UEM, v. 10, n. 3, p. 117-144, 2006.

BOSI, Ecléa. Memória e sociedade: lembranças de velhos. 4. ed. São Paulo: Companhia das Letras, 1995.

CARNEIRO, Henrique S. Comida e sociedade: significados sociais na História da Alimentação. História: Questões e Debates, nº 42, p. 71-80, 2005.

CERTEAU, Michel de; GIARD, Luce; MAYOL, Pierre. A invenção do cotidiano: 2. morar, cozinhar. Tradução Ephraim Ferreira Alves e Lúcia Endlich Orth. Petrópolis: Vozes, 1997.

CHOAY, Françoise. A alegoria do Patrimônio. Tradução de Luciano Vieira Machado. São Paulo: Estação liberdade: Editora UNESP, 2001.

CONSTITUIÇÃO da República Federativa do Brasil. São Paulo: Ática, 1989.

FERREIRA, Maria Letícia Mazzucchi. Patrimônio: discutindo alguns conceitos.

Diálogos, DHI/PPH/UEM, v. 10, n. 3, p. 79-88, 2006.

GONÇALVES, José Reginaldo Santos. Sistemas culinários como patrimônios culturais. In:

Antropologia dos objetos: coleções, museus e patrimônios. Rio de Janeiro: Coleção museu, memória e cidadania, 2007. p. 160-174.

GUSTO. Gastronomie: tendances et cultures, Paris, n. 3, 2007.

HALBWACHS, Maurice. A memória coletiva. Tradução Laurent Léon Schaffter. São Paulo: Vértice, 1990.

HOBSBAWM, Eric. Introdução: a invenção das tradições. In: HOBSBAWM, Eric; RANGER, Terence (orgs). A invenção das tradições. Tradução Celina Cardim Cavalcante. $2^{a}$ ed. São Paulo: Paz e Terra, 1997. MACIEL, Maria Eunice. Uma cozinha à brasileira. Estudos históricos, Rio de Janeiro, n. 33, 2004.

R. Inter. Interdisc. INTERthesis, Florianópolis, v.6, n.2, p. 30-44, jul./dez. 2009 
MENASCHE, Renata (Org). A agricultura familiar à mesa: saberes e práticas da alimentação no Vale do Taquari. Porto Alegre: UFRGS, 2007.

MENESES, Ulpiano T. Bezerra de; CARNEIRO, Henrique. A história da alimentação: balizas historiográficas, Anais do Museu Paulista, São Paulo, v. 5, p. 9-91, jan./dez. 1997.

ORIGEM. 180 anos da imigração alemã em Santa Catarina. Florianópolis: Empreendedor, s/d.

PANZUTTI, Nilce da Penha Migueles. Mulher rural: eminência oculta. Campinas, SP: Alínea, 2006.

PERROT, Michele. O gênero na cidade. In: As mulheres e os silêncios da história. Tradução Viviane Ribeiro. Bauru, SP: Edusc, 2005.

La place dês femmes á la cuisine / The role of women in the kitchen, Gusto. Gastronomie: tendances et cultures, Paris, n. 3, p. 10-13, 2007.

PIRES, Paulo dos Santos. A paisagem rural como recurso turístico. In: RODRIGUES, Adyr Balastreri (Org). Turismo rural: práticas e perspectivas. São Paulo: Contexto, 2001, p. 117-132.

PORTELLI, Alessandro. Tentando aprender um pouquinho. Algumas reflexões sobre a ética na História Oral. Projeto história, n. 15, p. 13-49, abr. 1997.

POULAIN, Jean-Pierre. Sociologias da alimentação: os comedores e o espaço social alimentar. Tradução Rossana Pacheco da Costa Proença, Carmem Sílvia Rial e Jaimir Conte. Florianópolis: UFSC, 2004.

SANTOS, Carlos Roberto Antunes dos. A alimentação e seu lugar na história: os tempos da memória gustativa. História: Questões \& Debates, Curitiba, $n^{\circ} 42$, p. 11 $31,2005$.

SCOTT, Joan W. Gênero: uma categoria útil de análise histórica. Educação e realidade, Porto Alegre, v. 16, n. 2, p. 5-22, jul./dez. 1990.

SORJ, Bila. Percepções sobre esferas separadas de gênero. In: ARAÚJO, Clara; SCALON, Celi (Orgs). Gênero, família e trabalho no Brasil. Rio de Janeiro: FGV, 2005, p. 79-88.

TULIK, Olga. Turismo rural. São Paulo: Aleph, 2003.

YÚDICE, George. A conveniência da cultura: usos da cultura na era global. Trad. Marie-Anne Kremer. Belo Horizonte: Ed. UFMG, 2004.

Dossiê:

Recebido em: 31/07/2009

Aceito em: 28/09/2009

R. Inter. Interdisc. INTERthesis, Florianópolis, v.6, n.2, p. 30-44, jul./dez. 2009 